\title{
Pedicled transverse rectus abdominis myocutaneous flap: A method for tunnelling with Dilson Luz vascular dilation wands for breast reconstruction
}

Sir,

Despite the popularity of free flaps and microsurgery, the pedicled transverse rectus abdominis myocutaneous (TRAM) flap remains a common autologous alternative for breast reconstruction. We describe a simple, quick and safe technique employed for the tunnelling process with the use of Dilson Luz vascular dilation wands (DLVDW).

Initial diathermy is used to set the plane and direction of undermining at both ends of the outlined tunnel, namely from the medial edge of the inframammary fold to the xiphoid process. This funnelling effect guides the blunt penetration of the initial wand with the smallest diameter. Once the tunnel dissection is complete, progressively larger bore wands are passed through to manipulate lateral detachment of the tunnel [Figures 1-3]. Minimal diathermy is used at the end of the tunnelling procedure to achieve a consistent diameter throughout. 


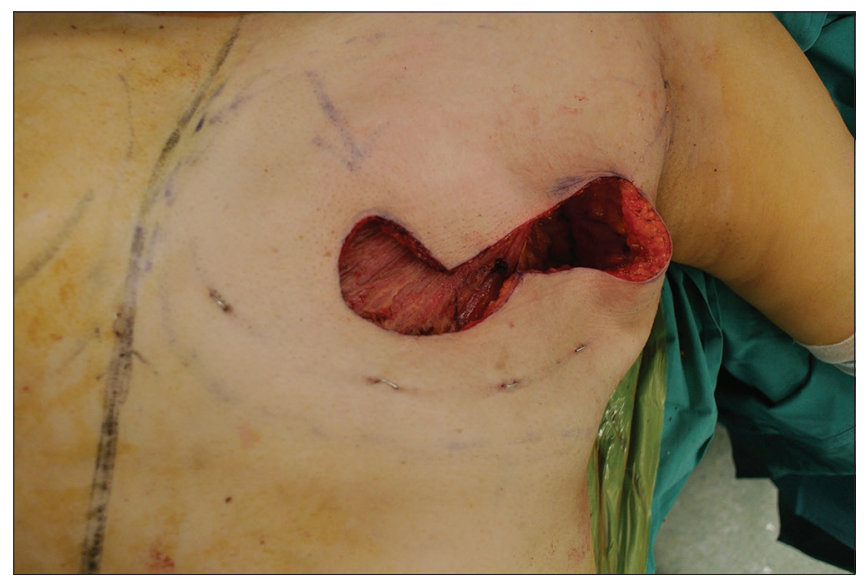

Figure 1: Left breast defect following mastectomy. Simple mastectomy with immediate reconstruction for cancer found in right upper quadrant

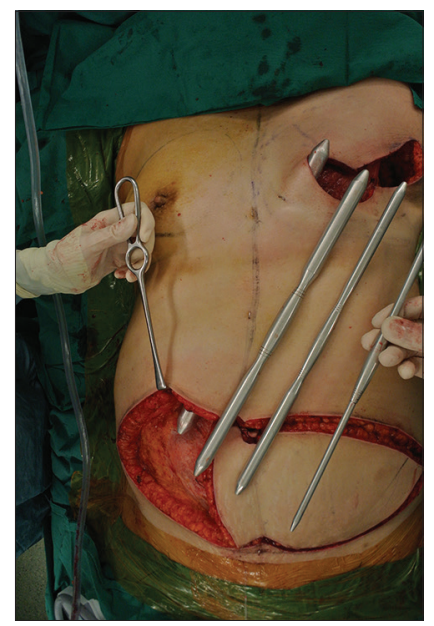

Figure 2: The set of Dilson Luz vascular dilation wands with increasing caliber. The smallest is used to begin the tunnelling process while the largest wand is used to create adequate detachment for the safe passage of the flap. Wand diameters used range from 6 to $20 \mathrm{~mm}$

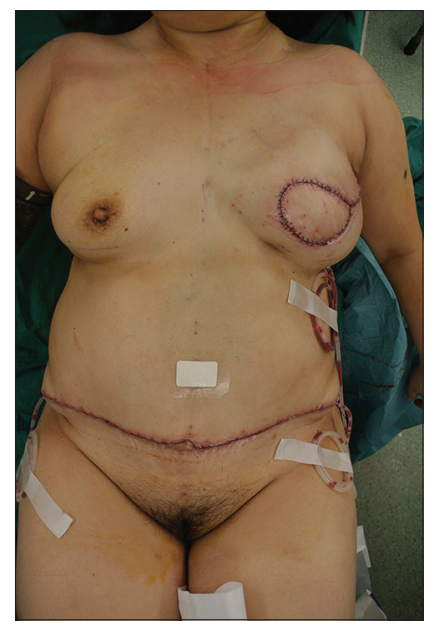

Figure 3: Reconstruction result post-operatively. Drains inserted inferolateral to the new breast mound and at the lateral edges of the donor site. Patient recovery was uneventful

Dilson Luz vascular dilator wands were initially designed as a less traumatic alternative to minimise the use of cautery during rhytidectomy. ${ }^{[1]}$ The technique has since been adopted for cutaneous liberation in reverse abdominoplasty. ${ }^{[2]}$ The rounded facet of the rigid steel wands stretches blood vessels to the point of rupture. As the diameter of the wands being inserted increases, there is progressive stretching and rupture of the vascular intima in the path of the instrument. This induces platelet recruitment and activation of the coagulation pathway. The small clots that form achieve haemostasis in the severe vascular extremities. ${ }^{[3]}$ The conventional method with the bipolar cautery requires additional diathermic haemostasis, and this is dependent on the surgeon's field of vision that may be concealed by the structure of the tunnel. Other methods of haemostasis include fibrin glue sprays, but this is costly and technical to set up.

In the authors' experience, wand undermining also diminishes the risk of 'buttonholing' of the cutaneous flap. The blunt technique takes advantage of fibrofatty attachment between the deep fascia and Scarpa's fascia, which gives way to perpendicular forces. ${ }^{[4]}$ Precision cutting with diathermy for flap detachment requires vigilant care to preserve Scarpa's fascia. This is also subject to competent retraction, adequate lighting and surgeon finesse.

da Luz $^{[1]}$ describes the technique's utilisation in 372 face and neck lifts and reported no single case of skin necrosis or haematoma formation. An exhaustive literature search has revealed no alternative techniques in pedicled TRAM cutaneous undermining. Nonetheless, further studies are needed to validate this technique for scarpa's fascial detachment against the conventional practice. In our practice, this technique has proven to be useful, effective and safe for flap interpolation. However, the method's simplicity is no substitute for surgical adeptness due to the proximity of the flap pedicle.

\section{Financial support and sponsorship}

Nil.

\section{Conflicts of interest}

There are no conflicts of interest.

\section{Christopher Tam Song, Joshua Perrett, Terence Goh, Bien Keem Tan}

Department of Plastic, Reconstructive and Aesthetic Surgery, Singapore General Hospital, Singapore 
Address for correspondence:

Dr. Bien-Keem Tan

Singapore General Hospital,

Outram Road, 169608 Singapore

E-mail: bienkeem@gmail.com

\section{REFERENCES}

1. da Luz DF, Wolfenson M, Figueiredo J, Didier JC. Full-face undermining using progressive dilators. Aesthetic Plast Surg 2005;29:95-9.

2. Yacoub CD, Baroudi R, Yacoub MB. Extended Reverse abdominoplasty. Rev Bras Cir Plást 2012;27:328-32.

3. Weis HJ. Hole of platelets in blood physiology. Clin Cir Am N 1988;4:810-3.

4. Forster DS. A note on scarpa's fascia. J Anat 1937;72 (Pt 1):130-1.
This is an open access article distributed under the terms of the Creative Commons Attribution-NonCommercial-ShareAlike 3.0 License, which allows others to remix, tweak, and build upon the work non-commercially, as long as the author is credited and the new creations are licensed under the identical terms.

\begin{tabular}{|l|l|}
\hline \multicolumn{2}{|c|}{ Access this article online } \\
\hline Quick Response Code: & Website: \\
\hline
\end{tabular}

How to cite this article: Song CT, Perrett J, Goh T, Tan BK. Pedicled transverse rectus abdominis myocutaneous flap: A method for tunnelling with Dilson Luz vascular dilation wands for breast reconstruction. Indian J Plast Surg 2017;50:119-21.

C 2017 Indian Journal of Plastic Surgery | Published by Wolters Kluwer - Medknow 